\title{
Editorial
}

\section{Management of Elevated Heart Rate in Essential Hypertension: Pathophysiological Insights and Therapeutic Approach}

For several aspects tachycardia may be considered the hidden risk factor.

In the general population tachycardia has been associated with increased total [1] and cardiovascular mortality (both for men and for women) [2], with an higher risk of vascular events [3,4] and with a worst prognosis after an acute vascular event [5]. Intriguing lines of research suggest that for each species of mammals exists a predetermined number of heart beats in a lifetime, with an inverse semilogarithmic relation between heart rate and life expectancy [6]. Nevertheless of this, although clinic resting heart rate (RHR) is one of the cardiovascular parameters more easily measurable, rarely the cardiovascular risk of the general population is also evaluated in relation to the RHR. Several limitations and uncertainties exist, first of all the lack of a common standard of normality of RHR and of a shared cutoff between "safe" RHR and elevated RHR. [1], the concrete and relevant different prognostic value of elevated RHR between the two genders, [7], and the need for a reliable way of ascertainment of RHR, able to avoid the risk of "white coat tachycardia", that may cause the measure of much higher values of RHR than the real for that subject (up to 45 beats per minutes higher) [8]. The evaluation and the clinical approach to elevated RHR in hypertensive subjects appear to be an even more complex problem. According to the latest guidelines provided by the European Society of Hypertension/European Society of Cardiology, it is suggested to the physicians to include the assessment of the RHR between the various clinical and instrumental elements useful to determine the cardiovascular risk of the hypertensive subject [9], but to date the value attributed to the RHR in the various clinical and experimental settings in which it has been evaluated is extremely variable. Suffice to say that the proportion of the patients with high blood pressure and tachycardia varies widely in the various studies addressing this issue. Probably because RHR is influenced by a wide range of factors, first of all low level of physical activity in sedentary subjects [10-12], or simply be the expression of a different pathologic condition not yet clinically manifest, although some of these conditions such as sedentary itself [13, 14] or obesity [15] may be considered reversible with proper interventions.

In the past decades, higher values of RHR have often been attributed to hypertensive subjects than healthy controls as a result of the effects of the different factors leading to the development of essential hypertension itself [16, 17], preceding to the increased sympathetic tone. More recent lines of research deeply investigated the issue regarding the relationship between elevated RHR, high blood pressure and the sympathetic nervous system activity, providing new data, and new points of view [18-20]. The need for a greater clarity of this issue arises also from the lack of an appropriate therapeutic approach for this category of subjects. Infact, to date we are unable to say whether a reduction of RHR in hypertensive subjects with elevated RHR could confer any benefit in terms of life expectancy, mostly taking into account the conflicting results achieved by the intervention studies in which various $\beta$-blockers (which are expected to be the optimal therapeutic choice for this category of patients) have been used [21]. Against this background, I would like to express deep gratitude to Mr. Kazim Baig and Mr. Aamer M. Khan for their help and support. The hot topic, "Management of elevated heart rate in essential hypertension: pathophysiological insights and therapeutic approach", firmly convinced that addressing certain issues about the pathophysiology, the clinical value and the therapeutic approach of tachycardia in hypertension would be useful to improve the approach to this category of patients and therefore may be of interest to the readers.

In this special issue, we have ten reviews: the first six reviews, written by leading authors in their respective fields, aimed to discuss and update the current knowledge about the optimal management of elevated heart rate in various clinical settings: diabetes [22], stroke [23], peripheral artery disease, [24], chronic kidney disease [25], heart failure [26] and finally obesity [27]. The following two reviews are quite linked, discussing the peculiarity represented by the presence in the same patient at the same time of elevated blood pressure and elevated heart rate. The seventh manuscript tries to answer the question of why not all the hypertensive subjects have also tachycardia [28] and the eighth one reviews the current evidence regarding the relationship between elevated heart rate and sympathetic nervous system in hypertension, critically revising the theory of "hyperkinetic circulation" [29]. The latest two reviews address the therapeutic aspect of the problem, discussing the ability of regular aerobic exercise to reduce heart rate [30], and the real efficacy of beta-blockers [31], that would be the best theoretical treatment for this subgroup of hypertensive patients, but is it really like that?

I strongly hope that the readers will appreciate the efforts of the authors and the editors, find the reviews interesting.

\section{REFERENCES}

[1] Palatini P, Rosei EA, Casiglia E, et al. Management of the hypertensive patient with elevated heart rate: statement of the second consensus conference endorsed by the European society of hypertension. J Hypertens 2016; 34(5): 813-21.

[2] Greenland P, Daviglus ML, Dyer AR, et al. Resting heart rate is a risk factor for cardiovascular and noncardiovascular mortality. Am J Epidemiol 1999; 149: 853-862.

[3] Schroll M, Hagerup LM. Risk factors of myocardial infarction and death in men aged 50 at entry. A ten-year prospective study from the Glostrup population studies. Dan Med Bull 1977; 24: 252-5.

[4] Sandset EC, Berge E, Kjeldsen SE, et al. rate as a predictor of stroke in high-risk, hypertensive patients with previous stroke or transient ischemic attack. J Stroke Cerebrovasc Dis 2014; 23(10): 2814-8.

[5] Tuttolomondo A, Pedone C, Pinto A, et al. Gruppo Italiano di Farmacoepidemiologia dell'Anziano (GIFA) researchers. Predictors of outcome in acute ischemic cerebrovascular syndromes: The GIFA study. Int J Cardiol 2008; 125(3): 391-6.

[6] Levine HJ. Rest heart rate and life expectancy. J Am Coll Cardiol 1997; 30(4): 1104-6.

[7] Palatini P, Julius S. Association of tachycardia with morbidity and mortality: Pathophysiological considerations. J Hum Hypertens 1997; 11(Suppl1): S19-27.

[8] Mancia G, Parati G, Pomidossi G, Grassi G, Casadei R, Zanchetti A. Alerting reaction and rise in blood pressure during measurement by physician and nurse. Hypertension 1987; 9: 209-15.

[9] The Task Force for the management of arterial hypertension of the european society of hypertension (ESH) and of european society of cardiology (ESC). 2013 ESH/ESC Guidelines for the management of arterial hypertension. J Hypertens 2013, 31: 1281-57.

[10] Di Raimondo D, Musiari G, Miceli G, Arnao V, Pinto A. Preventive and therapeutic role of muscle contraction against chronic diseases. Curr Pharm Des 2016; 22(30): 4686-99.

[11] Di Raimondo D. Editorial (Thematic Issue: Myokines and exercise training: more shadows than lights). Curr Pharm Des 2016; $22(24)$ : 3619-21. 
[12] Di Raimondo D, Tuttolomondo A, Musiari G, Schimmenti C, D'Angelo A, Pinto A. Are the myokines the mediators of physical activity-induced health benefits? Curr Pharm Des 2016; 22(24): 3622-47.

[13] Della Valle E, Stranges S, Trevisan M, Strazzullo P, Siani A, Farinaro E. Self-rated measures of physical activity and cardiovascular risk in a sample of Southern Italian male workers: the Olivetti heart study. Nutr Metab Cardiovasc Dis 2004; 14: 143-9.

[14] Di Raimondo D, Tuttolomondo A, Buttà C, et al. Metabolic and anti-inflammatory effects of a home-based programme of aerobic physical exercise. Int J Clin Pract 2013; 67(12): 1247-53.

[15] Straznicky NE, Grima MT, Eikelis N, et al. The effects of weight loss versus weight loss maintenance on sympathetic nervous system activity and metabolic syndrome components. J Clin Endocrinol Metab 2011;96(3): E503-8.

[16] Lund-Johansen P. Hemodynamics in early essential hypertension. Acta Med Scand 1967; 482(Suppl): 1-105).

[17] Julius S, Conway J. Hemodynamics studies in patients with borderline blood pressure elevation. Circulation 1968; 38: 282-8.

[18] Di Raimondo D, Miceli G, Casuccio A, et al. Does sympathetic overactivation feature all hypertensives? Differences of sympathovagal balance according to night/day blood pressure ratio in patients with essential hypertension. Hypertens Res 2016; 39(6): 440-8.

[19] Guild SJ, Barrett CJ, McBryde FD, Van Vliet BN, Head GA, Burke SL, Malpas SC. Quantifying sympathetic nerve activity: problems, pitfalls and the need for standardization. Exp Physiol 2010; 95(1): 41-50.

[20] Osborn JW. Hypothesis: set-points and long-term control of arterial pressure. A theoretical argument for a long-term arterial pressure control system in the brain rather than the kidney. Clin Exp Pharmacol Physiol 2005; 32(5-6): 384-93.

[21] Collins R, Peto R, MacMahon S, et al. pressure, stroke, and coronary heart disease, 2: short-term reductions in blood pressure: overview of randomized drug trials in their epidemiological context. Lancet 1990; 335: 827-38.

[22] Gouni-Berthold I, Hanssen R, Ravarani L, Berthold HK. Management of blood pressure and heart rate in patients with diabetes mellitus. Curr Pharm Des 2017; 23(31): 4573-82.

[23] Maida C, Tuttolomondo A, Di Raimondo D, Pinto A. Management of blood pressure and heart rate in patients with acute stroke. Curr Pharm Des 2017; 23(31): 4583-97.

[24] Signorelli SS. How to treat patients with essential hypertension and peripheral arterial disease. Curr Pharm Des 2017; 23(31): 4598-602.

[25] Kaltsatou A. Management of blood pressure and heart rate in chronic kidney disease. Curr Pharm Des 2017; 23(31): 4603-8.

[26] Kocyigit D, Gurses KM, Yalcin MU, Tokgozoglu L. Management of blood pressure and heart rate in acute decompensated heart failure with volume overload. Curr Pharm Des 2017; 23(31): 4609-19.

[27] Antza C, Stabouli S, Natsis M, Doundoulakis I, Kotsis V. Obesity-induced hypertension: new insights. Curr Pharm Des 2017; 23(31): 4620-5.

[28] Siński M, Jędrusik P, Lewandowski J. Why not all hypertensive patients are tachycardic at rest? Curr Pharm Des 2017; 23(31): 4626-34.

[29] Di Raimondo D, Musiari G, Grova G, Miceli G, Tuttolomondo A, Pinto A. The "neurocentric" approach to essential hypertension: how reliable is the paradigm of hyperkinetic hypertension? A focus on the sympathetic nervous system dysregulation in essential hypertensive patients with elevated resting heart rate. Curr Pharm Des 2017; 23(31): 4635-49.

[30] Perez-Quilis C, Kingsley JD, Malkani K, Cervellin G, Lippi G, Sanchis-Gomar F. Modulation of heart rate by acute or chronic aerobic exercise. potential effects on blood pressure control. Curr Pharm Des 2017; 23(31): 4650-57.

[31] Höcht C, Bertera FM, Del Mauro JS, Santander Plantamura Y, Taira CA, Polizio AH. What is the real efficacy of beta-blockers for the treatment of essential hypertension? Curr Pharm Des 2017; 23(31): 4658-77.

\section{Domenico Di Raimondo}

UOC di Medicina Interna con Stroke Care

Dipartimento Biomedico di Medicina Interna e Specialistica

Università degli Studi di Palermo

Palermo, Italy

Tel: 00390916552180

Fax: 00396552285 (fax)

E-mail: domenico.diraimondo@unipa.it 